\title{
Insomniacs get new mechanism sleep drug Belsomra
}

The US Food and Drug Administration (FDA) approval on August 13 of Merck's Belsomra (suvorexant) adds a new drug class to the set of treatment options available to insomnia sufferers. Unlike existing sedative hypnotic drugs, which induce sleepiness, Belsomra counters wakefulness. An orexin antagonist, it works by inhibiting the orexin neuropeptide signaling system, an important switch in the neural circuit that controls the sleep-wake cycle. The FDA has taken a characteristically cautious stance with the drug, particularly because of its impact on next-day driving at the doses Merck submitted in its original new drug application. The agency issued a complete response letter in July 2013, following which Merck resubmitted its new drug application after slashing the recommended doses in half. The Whitehouse Station, New Jersey-based firm is still waiting on a final Drug Enforcement Administration (DEA) classification before it can launch and market the drug, which has aroused expectations because of its relatively benign safety and tolerability profile in comparison with currently used agents.

Most insomnia drugs are agonists of the $\gamma$-aminobutyric acid A $\left(\mathrm{GABA}_{\mathrm{A}}\right)$ receptor. They induce sleep by mimicking the effects of the inhibitory neurotransmitter GABA. As well as promoting sleep, they affect memory and can lead to aberrant behaviors during sleep, including somnambulism, eating, sex and even driving. Belsomra is a dual orexin receptor antagonist. It induces sleep by blocking two wakefulness-promoting neuropeptide hormones orexin $\mathrm{A}$ and $\mathrm{B}$ from binding their widely distributed receptors Orexin- $1\left(\mathrm{OX}_{1} \mathrm{R}\right)$ and $\mathrm{OX}_{2} \mathrm{R}$.

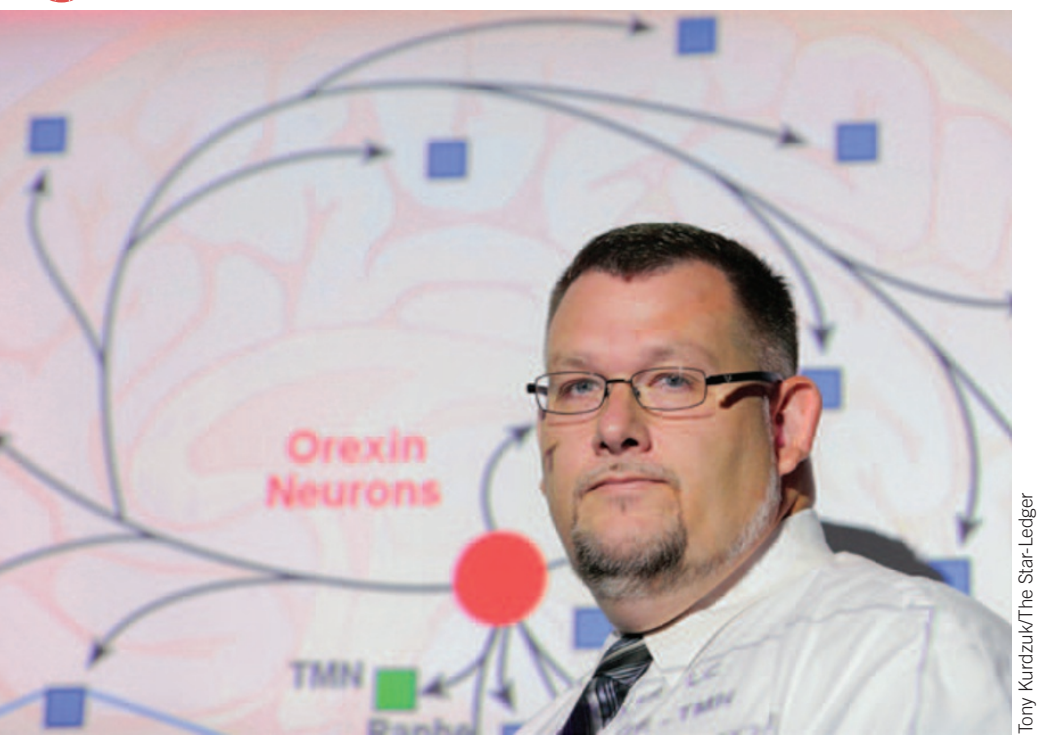

Merck executive director of neuroscience early discovery John Renger led the research for the new drug Belsomra at the New Jersey-based pharma.
Orexin seems to promote wakefulness. In the human brain, there are about 70,000 orexin-producing neurons located in the lateral and posterior hypothalamus. The two types of orexin peptides are derived from a common precursor, though they differ in their binding affinity: $\mathrm{OX}_{1} \mathrm{R}$ has higher affinity for Orexin $\mathrm{A}$, whereas $\mathrm{OX}_{2} \mathrm{R}$ binds both peptides. Orexin-A and $\mathrm{B}$ are excitatory neuropeptide hormones that promote wakefulness by sending inhibitory signals to the ventrolateral preoptic nucleus, an area of the hypothalamus with a high concentration of GABA-producing neurons. Individuals with narcolepsy, a condition characterized by extreme daytime sleepiness, have a deficiency in orexin-producing cells, possibly caused by an autoimmune attack. The orexin system also plays a direct role in stimulating food intake and arousal and has indirect effects-mediated by the autonomic nervous system-on raising body temperature and energy metabolism. Genetic knockout mice lacking the gene for orexin exhibit narcolepsy and dogs that lack a functional orexin receptor also have narcolepsy.

In human trials, Belsomra appears to tackle sleep initiation and maintenance difficulties. In a phase 3 trial, participants who were on Belsomra for 12 months reported that, two months after switching to placebo, they took on average 14.9 minutes longer to fall asleep and slept for 21.6 minutes less than those who stayed on the drug. One recent study of Ambien (zolpidem) reported that after eight months, those on the drug had a 40-minute improvement in total sleep time over those on placebo (Sleep 35, 1551-1557, 2012). Direct comparisons with other agents are difficult in the absence of headto-head studies, however. The sleeping pattern that arises from the consumption of Belsomra does not replicate normal physiological sleepit appears to favor rapid-eye movement (REM) sleep over non-REM sleepand those who take it experience a great deal of somnolence on waking. "Actually [they are] pretty much like people who suffer from narcolepsy or even insomnia," says Daniel Hoyer, who chairs the Department of Pharmacology and
Therapeutics in the University of Melbourne, in Melbourne, Australia.

The effects may be related to Belsomra's in vivo activity profile. Studies in animal knockouts show that $\mathrm{OX}_{2} \mathrm{R}$ is more important in regulating sleep behavior than $\mathrm{OX}_{1} \mathrm{R}$, and Belsomra's in vivo activity profile may not be optimal. Hoyer and colleagues recently reported data from competition experiments in mice using radioligands suggesting that Belsomra-and several other so-called dual-acting orexin antagonistsmay in fact have selectivity for one or the other orexin receptors (Front. Neurosci. 7, e230, 2013). Almorexant, which was the first orexin antagonist to enter clinical trials but which was withdrawn because of its drug-drug interaction profile, has, under extended incubation conditions, greater in vivo affinity for $\mathrm{OX}_{2} \mathrm{R}$. By contrast, Belsomra has, over time, greater affinity for $\mathrm{OX}_{1} \mathrm{R}$. That could account for some of the sleep disturbances seen with the drug. "It will be debated until someone has a proof of concept of an $\mathrm{OX}_{2} \mathrm{R}$ antagonist in humans. Until then, the jury is out," says Hoyer.

In the meantime, physicians and patients are about to discover the real potential of the new drug class-and drug companies will continue to explore its potential as well. "While suvorexant is the first orexin antagonist to be approved for any indication, it certainly won't be the only one for insomnia-and insomnia probably won't be the only indication for orexin antagonists," says David Neubauer, associate professor of psychiatry and behavioral science at Johns Hopkins University School of Medicine, in Baltimore.

Belsomra is expected to be available in late 2014 or early 2015. This is based on the assumption that the DEA will issue a final decision on the scheduling for Belsomra by this time, according to Merck spokeswoman Pamela Eisele. Earlier this year, the DEA proposed a schedule IV classification under the Controlled Substances Act, a designation reserved for substances with a low potential for abuse or for physical or psychological dependence. That puts Belsomra on a par with benzodiazepines and the so-called 'Z-drugs', such as Ambien and Sonata (zaleplon), which are not benzodiazepines but which have similar effects. "The classification of suvorexant was a conservative measure on the part of the DEA," Neubauer says. "There is no evidence of abuse, and the mechanism of action would not predict physiologic dependence." However, one study, in individuals with a history of recreational use of sedatives, concluded that, among drug users, its potential for abuse was similar to that of Ambien.

Cormac Sheridan Dublin 